\title{
A Potato Gene Encoding a WRKY-like Transcription Factor Is Induced in Interactions with Erwinia carotovora subsp. atroseptica and Phytophthora infestans and Is Coregulated with Class I Endochitinase Expression
}

\author{
Alia Dellagi, ${ }^{1}$ Jacqueline Heilbronn, ${ }^{1}$ Anna O. Avrova, ${ }^{1}$ Marcos Montesano, ${ }^{3}$ E. Tapio Palva, ${ }^{3}$ \\ Helen E. Stewart, ${ }^{2}$ Ian K. Toth, ${ }^{1}$ David E. L. Cooke, ${ }^{1}$ Gary D. Lyon, ${ }^{1}$ and Paul R. J. Birch ${ }^{1}$ \\ ${ }^{1}$ Unit of Mycology, Bacteriology and Nematology and ${ }^{2}$ Unit of Applied Genetics, Scottish Crop Research \\ Institute, Invergowrie, Dundee, DD2 5DA, U.K.; and ${ }^{3}$ Department of Biosciences, Division of Genetics, \\ Box 56, FIN.00014, University of Finland, Helsinki \\ Accepted 6 July 2000.
}

\begin{abstract}
A potato gene encoding a putative WRKY protein was isolated from a cDNA library enriched by suppression subtractive hybridization for sequences upregulated $1 \mathrm{~h}$ postinoculation with Erwinia carotovora subsp. atroseptica. The cDNA encodes a putative polypeptide of 172 amino acids, containing a single WRKY domain with a zinc finger motif and preceded by a potential nuclear localization site. StWRKY1 was strongly upregulated in compatible, but only weakly in incompatible, interactions with Phytophthora infestans where, in all cases, it was coregulated with class I endochitinase, associating its expression with a known defense response. Whereas $S t-W R K Y 1$ was strongly induced by $E$. carotovora culture filtrate $(\mathrm{CF})$, confirming it to be an elicitor-induced gene, no such induction was detected after treatment with salicylic acid, methyl jasmonate, ethylene, or wounding. St-WRKY1 was upregulated by treatment of potato leaves with CFs from recombinant Escherichia coli containing plasmids expressing $\boldsymbol{E}$. carotovora pectate lyase genes pelB and pelD, suggesting that either proteins encoded by these genes, or oligogalacturonides generated by their activity, elicit a potato defense pathway associated with St-WRKY1.
\end{abstract}

Additional keywords: late blight, pathogen, plant.

Plants are subject to different forms of pathogen attack. In the compatible interaction between host and pathogen, infection is successful and leads to symptom development. In other cases, absence of disease can be accompanied by a localized cell death called the hypersensitive response (HR), which results from recognition between products of a dominant $R$ gene in the host and a corresponding avirulence $(A v r)$ gene in the pathogen (Dangl et al. 1996; Hammond-Kosack and Jones

Corresponding author: Paul R. J. Birch; Telephone: +44 1382 562731; Fax: +44 1382 562426; E-mail: pbirch@scri.sari.ac.uk

Nucleotide and/or amino acid sequence data can be found at the EMBL data base as accession number AJ278507 for the St-WRKY1 gene.
1997). Potential pathogens may elicit the generation of lowmolecular-weight molecules, including reactive oxygen species (ROS), ethylene, salicylic acid (SA), and jasmonic acid (JA), that act as signals to trigger many independent or interacting biochemical pathways in the plant (Reymond and Farmer 1998). These may result in the HR or the enhancement of preformed barriers and de novo synthesis of compounds such as pathogenesis-related (PR) proteins, all of which contribute to disease resistance (Somssich and Hahlbrock 1998).

The activation of defense responses may be elicited by signals derived either directly from the pathogen or generated by degradation of the plant cell wall (Davis et al. 1984; Palva et al. 1993). Recent studies support a model in which such pathogeninduced signals are transmitted through a membrane receptor coupled with a kinase activity (receptor-like kinase; RLK) that then initiates a phosphorylation cascade leading to the induction or repression of target genes (Lease et al. 1998; Czernic et al. 1999). Among the target genes are a variety of transcription factors that mediate the regulation of a variety of plant defense responses, including the upregulation of $P R$ genes, through recognition of specific DNA sequences in their promoter regions (Rushton and Somssich 1998). A new family of DNA-binding proteins containing the consensus sequence "WRKY" has recently been identified, some of which are involved in elicitor induction of $P R$ genes (Rushton et al. 1995; Rushton et al. 1996; Wang et al. 1998; Eulgem et al. 1999; Yang et al. 1999), and others may be involved in the wound response (Hara et al. 2000). WRKY proteins recognize two types of elicitor-responsive elements in the promoters of $P R$ genes, called $\mathrm{W}$ boxes, the first containing the motif (T)TGAC(C), and the second comprising TGAC- $\mathrm{N}_{\mathrm{x}}$-GTCA (Rushton and Somssich 1998).

In this article, we describe the isolation of a potato cDNA encoding a putative member of the WRKY DNA-binding protein family, St-WRKY1, which is induced during the compatible interaction with the soft rot bacterial pathogen Erwinia carotovora subsp. atroseptica. We investigate the regulation of this gene during both compatible and incompatible interac- 
tions with the fungal pathogen Phytophthora infestans. Its expression is also studied in response to the elicitors SA, methyl jasmonate (MeJA), ethylene, and E. carotovora culture filtrates $(\mathrm{CF})$, and also in response to wounding. In each case, we compare the expression of St-WRKYl with that of class I basic chitinases (PR3) from potato that have previously been shown to be induced by $P$. infestans and by fungal elicitor treatment (Beerhues and Kombrink 1994). Indeed, a related class I chitinase promoter region from tobacco has been shown to contain a W box that may be involved in binding to a WRKY protein (Fukuda and Shinshi 1994). Finally, given that plant cell wall degradation may generate elicitors, we address the additional question of whether the presence or activity of specific pectin-degrading enzymes from E. carotovora leads to upregulation of $S t-W R K Y 1$. For this, acellular extracts from recombinant Escherichia coli containing plasmids expressing E. carotovora pectate lyase (pel) genes were used as elicitors.

\section{RESULTS}

\section{Isolation of a cDNA encoding a putative WRKY transcription factor.}

A subtracted cDNA library enriched with potato genes upregulated $1 \mathrm{~h}$ after inoculation with E. carotovora subsp. atroseptica was generated by suppression subtractive hybridization (SSH) (Diatchenko et al. 1996). Following hybridization screening of the cDNA library as described previously (Birch et al. 1999), sequencing of subtracted clones revealed a cDNA fragment, A1, of 446 base pairs (bp) sharing 70\% similarity with a cDNA isolated from sweet potato, $S P 8 B F$, encoding a DNA-binding protein with probable transcription factor activity (Ishiguro and Nakamura 1994). The $5^{\prime}$ and $3^{\prime}$ ends of the cDNA from which A1 was derived were obtained by rapid amplification of cDNA ends (RACE). The full-length cDNA was then amplified by polymerase chain reaction (PCR) using primers designed to anneal to either end of the gene sequence.

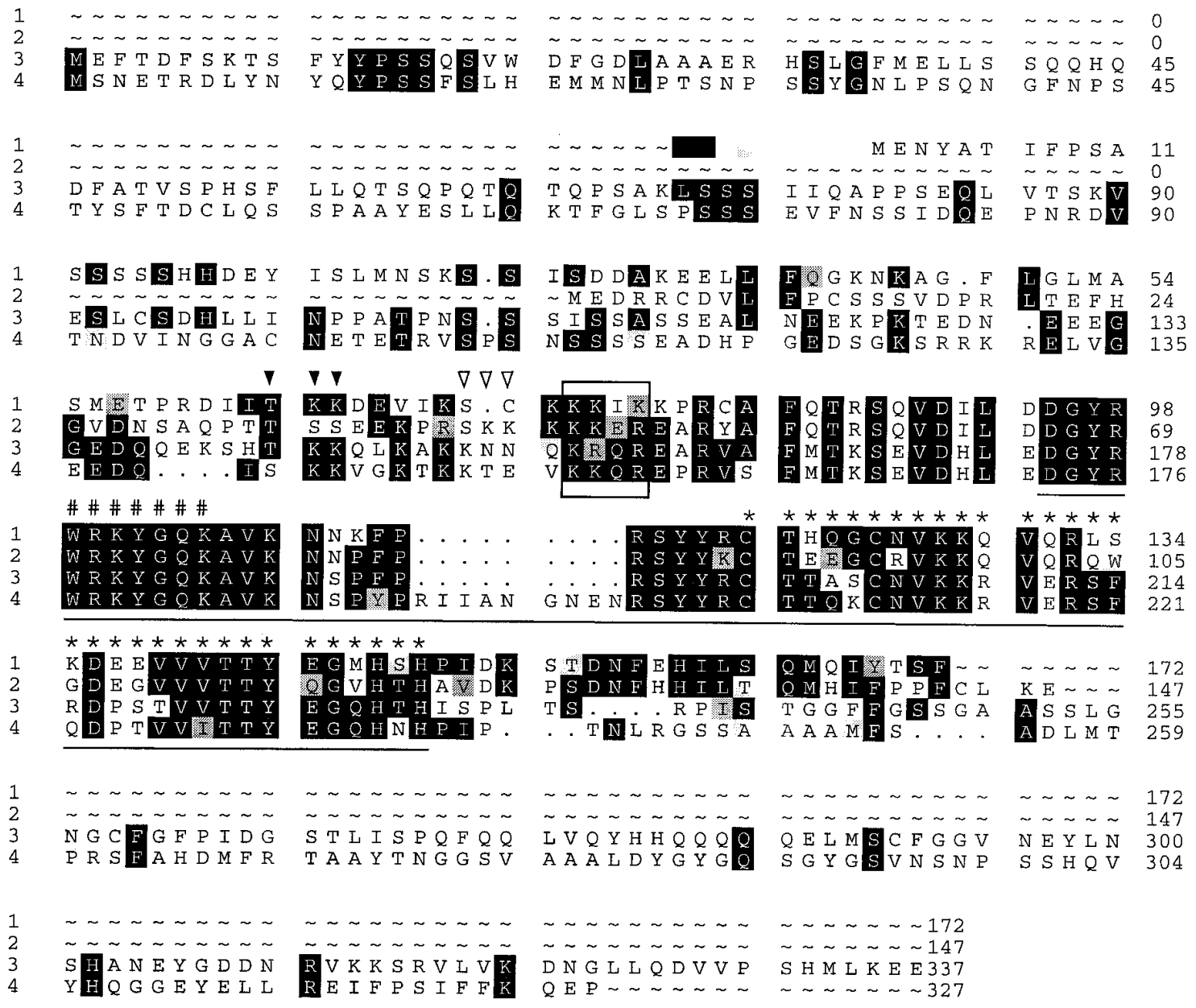

Fig. 1. Amino acid sequence alignment of the predicted potato St-WRKY1 (sequence 1) polypeptide with three closely related putative group 2 WRKY proteins from Arabidopsis thaliana: accession numbers AC005397 (sequence 2), AC002337 (sequence 3), and AL021713 (sequence 4). The proteins were aligned using the PILEUP and LINEUP programs of the Wisconsin Genetics Computer Group software package (Madison, WI, U.S.A.) and are displayed using PRETTYBOX. Black shading shows identical amino acids and gray shading indicates conserved substitutions. A possible conserved protein kinase $\mathrm{C}$ site is indicated by shaded arrows for sequences 1,3 , and 4 , and by unshaded arrows for sequence 2 . The WRKYGQK motif is indicated by \#, a zinc finger motif is indicated by *, and a putative nuclear localization site is boxed. The WRKY domain, as defined by Eulgem et al. (1999) and aligned for the dendrogram in Figure 2, is underlined. 
The entire cDNA fragment is $633 \mathrm{bp}$ and contains an open reading frame of 519 bp flanked by 5'- and 3'-untranslated regions (UTRs) of 39 and $45 \mathrm{bp}$, respectively. The deduced polypeptide is 172 amino acids (aa) long, with a calculated molecular mass of $19.86 \mathrm{kDa}$.

Comparison of the putative polypeptide encoded by this cDNA with sequences in international databases revealed similarity (2.5e-06 to 2.6e-39) to a class of related DNA-binding proteins. A common feature of these proteins is a conserved amino acid sequence, WRKYGQK. Members of this family (WRKY proteins) bind to $\mathrm{W}$ boxes in promoter regions of $P R$ genes (Rushton and Somssich 1998). Therefore, we named the gene isolated in this study $S t-W R K Y 1$, because it encodes a putative protein containing a WRKY motif at amino acid position 98. An alignment of the putative St-WRKY1 protein with related sequences (Fig. 1) indicates a putative zinc finger motif $\left(\mathrm{C}-\mathrm{X}_{4}-\mathrm{C}-\mathrm{X}_{22-23}-\mathrm{H}-\mathrm{X}_{1}-\mathrm{H}\right)$ near the $\mathrm{C}$ terminus of the WRKY domain and a putative nuclear localization site.

\section{Alignment of WRKY domains reveals distinct classes.}

WRKY proteins possess either two (group 1) or one (group 2) copies of the conserved WRKY domain, which Eulgem et

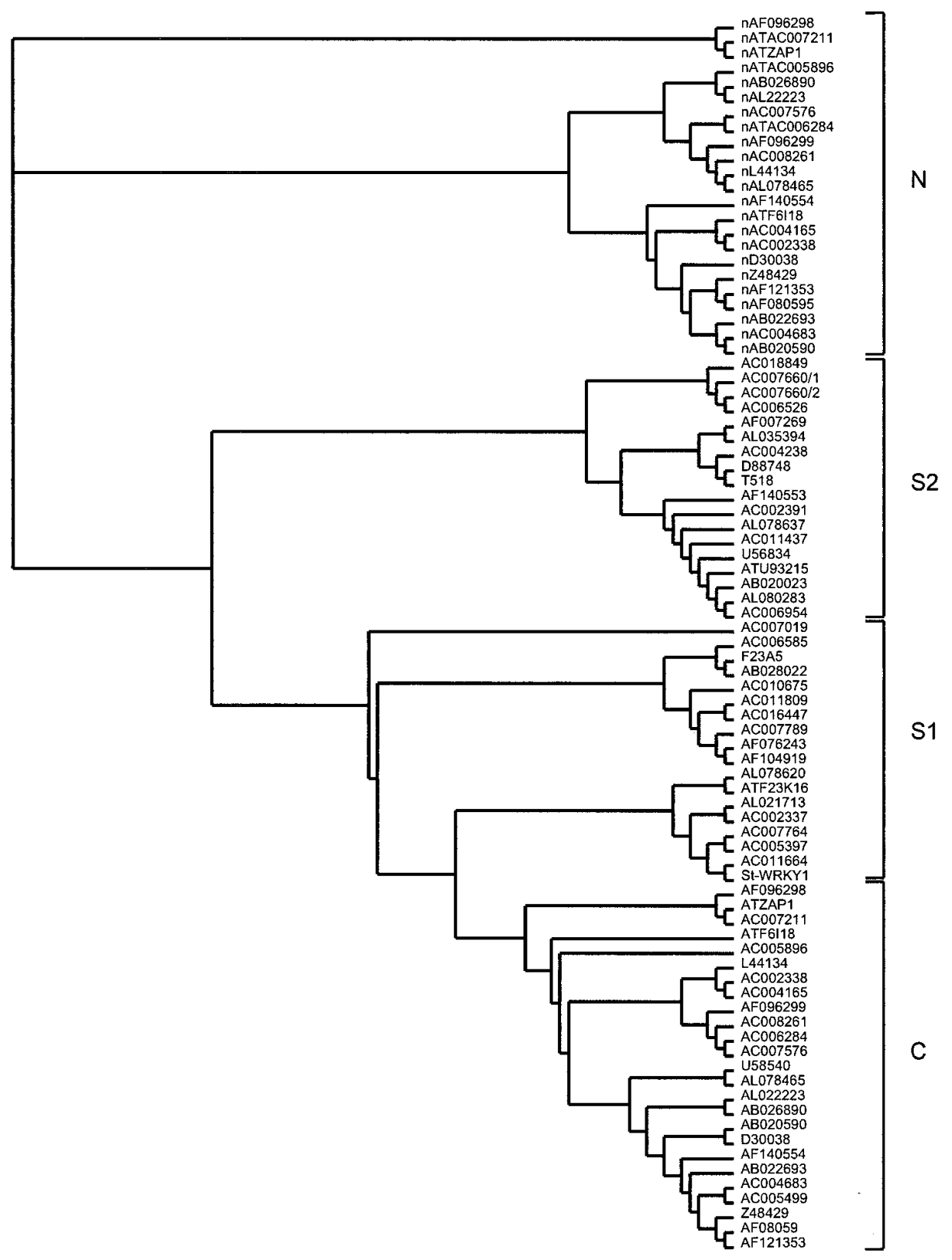

Fig. 2. Relationships of WRKY domains from group 1 proteins. The WRKY domain from St-WRKY1 was compared with those encoded by 59 putative genes in GenBank (accession numbers to the right of the tree) using CLUSTALW (Thompson et al. 1994) and edited using GeneDoc (Nicholas et al. 1997). The phylogenetic analysis was performed using PROTDIST and NEIGHBOUR packages in PHYLIP (Phylogenetic Inference Package version 3.5c; J. Felsenstein, Department of Genetics, University of Washington, Seattle, WA, U.S.A.). Clade C comprises C-terminal domains and clade N comprises N-terminal domains of group 1 proteins. Clades S1 and S2 are domains from group 2 proteins. 
al. (1999) defined as a 56- to 59-aa region encompassing the WRKY sequence and zinc finger motif. A search of international databases revealed reliable similarities to 60 putative gene sequences, of which 23 encode group 1 and 37 encode group 2 WRKY proteins. St-WRKYI encodes an additional putative group 2 protein. Thirty-eight of the sequences from databases are derived from Arabidopsis thaliana, suggesting large gene families and considerable complexity in function, specificity, or both. To attempt a structural classification of these families, we aligned the WRKY domains to generate a dendrogram (Fig. 2).

In the case of group 2 proteins, two clades exist (S1 and S2, in which $\mathrm{S}$ denotes proteins with a single WRKY domain) (Fig. 2). Whereas S2 domains form a distinct clade, S1 domains (of which St-WRKY1 is a member) share similarity with the C-terminal (clade C) WRKY domains of group 1 proteins and, indeed, the domains of an additional two group 2 proteins fell within the $\mathrm{C}$ clade. In contrast, the $\mathrm{N}$-terminal domains of group 1 proteins form an additional, distinct clade. Nevertheless, groupings within the $\mathrm{N}$ clade are similar to groupings within the $\mathrm{C}$ clade, suggesting that, when the $\mathrm{N}$-terminal domains of two proteins are highly similar to each other, their corresponding C-terminal domains are also similar to each other (Fig. 2). Thus, the two domains appear to have coevolved, implying that differences between $\mathrm{N}$ - and $\mathrm{C}$-terminal domains are highly selected for and, therefore, likely to represent distinct functions. An alignment of 10 C-terminal WRKY domains (representing the full range of variation within this clade) with their corresponding N-terminal domains reveals that the greatest variation between these domains is found within the zinc finger motif. Amino acid positions are conserved within either the C-terminal (Fig. 3, top) or the N-terminal (Fig. 3, bottom)

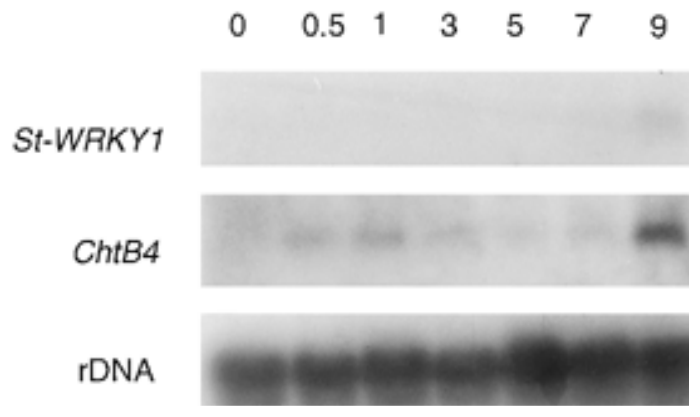

Fig. 4. Northern (RNA) hybridization of the potato $S t-W R K Y 1$ gene (StWRKY1), basic chitinase (ChtB4), and, as a control, ribosomal DNA (rDNA), to $20 \mu \mathrm{g}$ of total RNA (each lane) extracted from control potato leaf material treated only with $\mathrm{MgSO}_{4}$ (lane 0) and leaf material $30 \mathrm{~min}$ (lane 1/2), $1 \mathrm{~h}$ (lane 1), $3 \mathrm{~h}$ (lane 3), $5 \mathrm{~h}$ (lane 5), $7 \mathrm{~h}$ (lane 7), and $9 \mathrm{~h}$ (lane 9) postinoculation with Erwinia carotovora subsp. atroseptica.

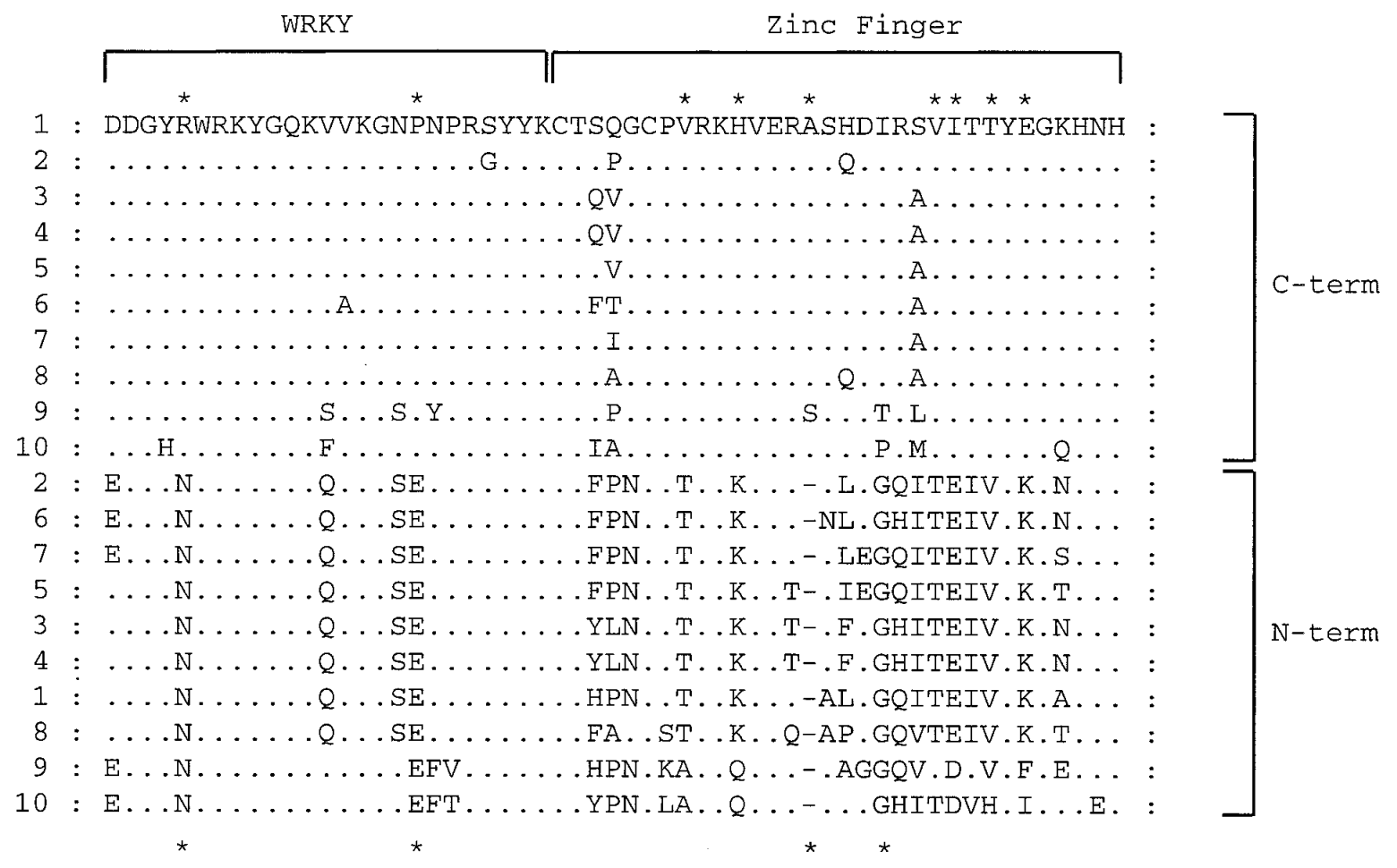

Fig. 3. Alignment of putative amino acid sequences from $10 \mathrm{~N}$-terminal (N-term) and their corresponding C-terminal (C-term) WRKY domains. Accession numbers from which these sequences are derived are D30038 (from Spf1; Ishiguro and Nakamura 1994) (sequence 1), AB020590 (sequence 2), AF121353 (WRKY1; Eulgem et al. 1999) (sequence 3), AF080595 (sequence 4), Z48429 (sequence 5), AB022693 (sequence 6), AC004683 (sequence 7), AF140554 (sequence 8), ATZAP1 (ZAP1; de Pater et al. 1996) (sequence 9), and AF096298 (sequence 10). The WRKY domain is divided into the regions containing the WRKY sequence and the zinc finger motif (indicated at the top). The entire sequence of the C-terminal domain from protein 1 is given. Identical amino acids are indicated with a dot (.) and the amino acid letter is shown where differences to sequence 1 occur. Amino acids conserved in the C-terminal but not the $\mathrm{N}$-terminal domain are indicated by * at the top of the figure, whereas conserved $\mathrm{N}$-terminal domain-specific amino acids (and an amino acid absent from the N-terminal domain) are indicated by * at the bottom of the figure. Alignments were performed using CLUSTALW (Thompson et al. 1994) and edited using GeneDoc (Nicholas et al. 1997). 
domains and are different than the other domain. Out of 10 such amino acid positions, eight are observed in the zinc finger region (Fig. 3).

\section{Temporal expression of $S t$-WRKY1 when potato leaves are challenged with $E$. carotovora subsp. atroseptica.}

The expression of $S t$-WRKYI was investigated in potato leaves inoculated with $E$. carotovora subsp. atroseptica across a 9-h time course (Fig. 4). WRKY genes share little homology at the DNA level; therefore, the entire $S t-W R K Y 1$ cDNA was used as a hybridization probe for Northern (RNA) analysis. For comparison, expression of a potato class I endochitinase gene (ChtB4) (Beerhues and Kombrink 1994) was also investigated. DNA homology between $C h t B 4$ and other $C h t B$ genes (Beerhues and Kombrink 1994) suggests that, although highly stringent hybridization conditions were used, the full-length ChtB 4 cDNA probe used in this study could detect expression of all members of this class I endochitinase gene family.

Despite the isolation of $S t-W R K Y 1$ at $1 \mathrm{~h}$ postinoculation (hpi) using SSH, a detectable increase in St-WRKY1 transcript levels was observed only at 7 and 9 hpi using Northern (RNA) analysis. However, the SSH procedure is greater than 1,000fold more sensitive than Northern analysis (Diatchenko et al. 1996), suggesting that, if the $S t$-WRKY1 gene is upregulated at the 1-h time point, such expression is below the threshold of detection by Northern hybridization.
In contrast to $S t$-WRKY1, chitinase gene expression was detectable $30 \mathrm{~min}$ postinoculation but also dramatically increased at 9 hpi (Fig. 4). Nevertheless, both St-WRKY1 and chitinase are clearly upregulated in potato by E. carotovora subsp. atroseptica inoculation.

\section{Temporal expression of $S t$-WRKY1 when potato leaves are challenged with compatible and incompatible races of $P$. infestans.}

The expression of $S t-W R K Y 1$ was also investigated in potato leaves inoculated with the late blight pathogen $P$. infestans, because this pathogen offers the opportunity to compare compatible and incompatible interactions (Fig. 5). Four different potato cultivars were tested with virulent and avirulent fungal isolates. Although cvs. Stirling, 1512 c(16), and Pentland Ace contain $R$ genes leading to HR with avirulent $P$. infestans isolates, cv. Bintje is successfully infected by all known $P$. infestans isolates. Again, expression of chitinase, using the ChtB4 probe, was also investigated for comparison. RNA was extracted from each cultivar, uninfected and 15, 48, and 72 hpi with either a compatible or an incompatible race of $P$. infestans. These time points have been used recently in our laboratory to demonstrate the upregulation of the potato cyp gene specifically in incompatible interactions with $P$. infestans (Avrova et al. 1999).

The expression of $S t$-WRKYI and basic chitinase in interactions with 'Bintje', '1512 c(16)', and 'Stirling' is shown in
A

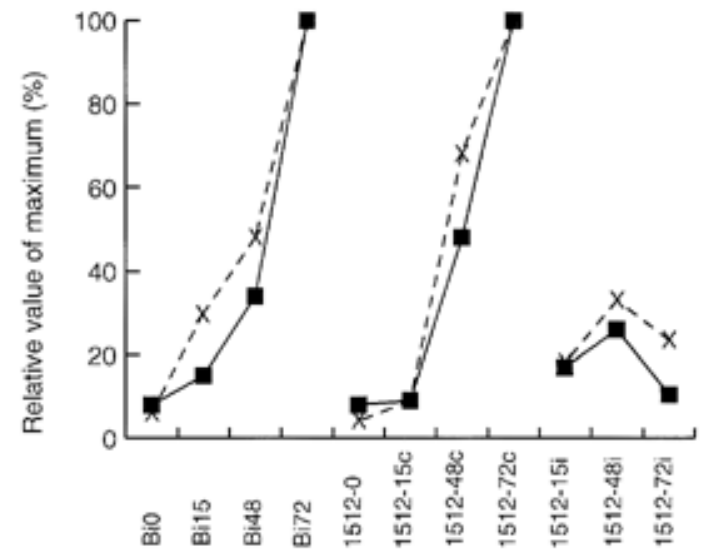

B

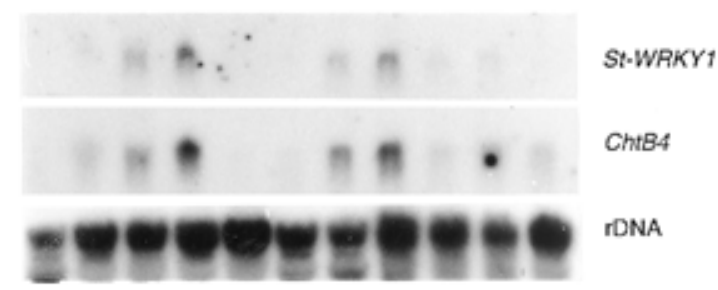

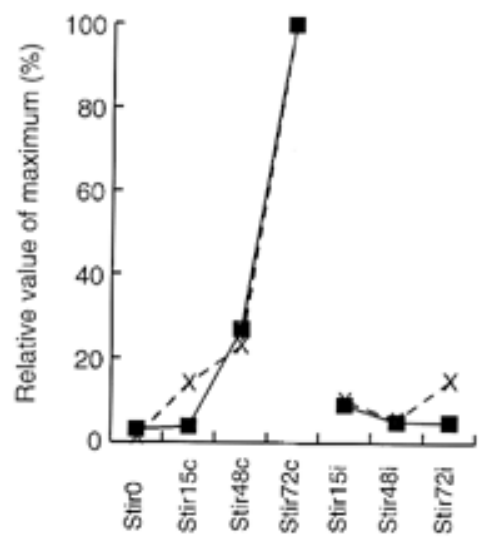

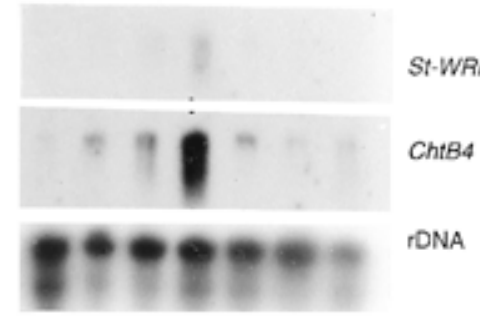

Fig. 5. Northern (RNA) hybridization of the $S t-W R K Y 1$ gene (St-WRKY1), basic chitinase (ChtB4), and, as a control, ribosomal DNA (rDNA), to $20 \mu \mathrm{g}$ of total RNA (each lane) extracted from 'Bintje' uninfected (Bi0) and 15, 48, and $72 \mathrm{~h}$ (Bi15, Bi48, and Bi72, respectively) postinoculation with a Phytophthora infestans-compatible isolate; ' 1512 (c)' uninfected (1512-0) and 15, 48, and $72 \mathrm{~h}$ postinoculation with a compatible isolate (1512-15c, 1512$48 \mathrm{c}$, and 1512-72c, respectively) and an incompatible isolate (1512-15i, 1512-48i, and 1512-72i, respectively) of P. infestans; 'Stirling' uninfected (Stir0), and 15, 48, and $72 \mathrm{~h}$ postinoculation with a compatible isolate (Stir-15c, Stir-48c, and Stir-72c, respectively) and an incompatible isolate (Stir15i, Stir-48i, and Stir-72i, respectively) of $P$. infestans. B and $\mathbf{D}$, Northern hybridizations; $\mathbf{A}$ and $\mathbf{C}$, the equivalent intensities of hybridized bands obtained after densitometric scanning, respectively. The amounts of St-WRKY1 (⿴) and ChtB4 (X) transcripts were normalized by comparison to rDNA hybridization and were plotted as a percentage of the highest value for each cultivar. 
Figure 5; the result for 'Pentland Ace' was not shown because it was similar to ' $1512 \mathrm{c}(16)$ '. The St-WRKY1 transcript was detected in compatible interactions from 15 hpi (in 'Bintje'), with the highest level being at 72 hpi in all cultivars. In contrast, only a relatively weak expression was detected in the incompatible interactions at the 15 and 48 hpi time points for 'Pentland Ace' and '1512 c(16)' and the 15 hpi time point for 'Stirling' (Fig. 5). Interestingly, a highly similar expression pattern was observed for chitinase (Fig. 5). Given that, in all cases, potato leaves were inoculated by evenly spraying equal amounts of $P$. infestans zoospores across the leaf surface, differences between compatible and incompatible isolates are unlikely to be due to differences in the numbers of plant cells being affected.

Recent evidence, using $P$. sojae infection of parsley (a nonhost interaction), has suggested that WRKYl gene expression is local, rapidly induced, and transient in planta (Eulgem et al. 1999). Indeed, higher levels of St-WRKY1 expression were observed at the 15 hpi time point of the incompatible interactions than at the equivalent time point of the compatible interactions for 'Stirling', 'Pentland Ace', and '1512 c(16)' (Fig. 5), suggesting that expression of the gene may peak at an earlier time in the incompatible interactions. Therefore, we decided to study earlier time points in the potato-P. infestans interactions to see if $S t-W R K Y 1$ expression is detectable before 15 hpi. RNA was extracted at 1, 3, 5, 10, 15, 48, and 72 hpi from 'Stirling' and '1512 c(16)' with either the avirulent or virulent $P$. infestans race. The results of the analysis were similar for both cultivars, so only those for 'Stirling' (uninfected and 1, 3, 5, and 10 hpi) are shown (Fig. 6).

Both St-WRKY1 and chitinase gene expression were detectable at the 1 hpi time point in both incompatible and compatible interactions (Fig. 6). Expression then decreased in these interactions at 3 hpi for both genes (Fig. 6), before increasing again at $5 \mathrm{hpi}$ in the compatible interaction. Moreover, expression of both genes then increased (as shown previously; Fig. 5) from the 15 to 72 hpi time points (data not shown in Fig. 6). Thus, both $S t$-WRKYI and class I endochitinase have a phasic expression in compatible and incompatible potato- $P$. infestans interactions but are only weakly detectable in the latter.

\section{Signaling pathways involved in St-WRKY1 induction.}

Many plant defense response genes, including those encoding PR proteins, are induced by one or all of the following compounds: SA, MeJA (volatile counterpart of JA), or ethylene. Some are also induced after wounding (Reymond and Farmer 1998). The signaling pathways involving SA, JA, and ethylene are well characterized in A. thaliana and are separate, although some cross talk occurs between them. In addition, $\mathrm{CF}$ from $E$. carotovora subsp. carotovora has been shown to induce plant defense genes independently of the SA pathway (Vidal et al. 1997). To investigate whether the St-WRKY1 gene was upregulated by any of these potential elicitors, RNA was extracted for Northern analysis from leaf material treated with E. carotovora subsp. carotovora $\mathrm{CF}, \mathrm{MeJA}, \mathrm{SA}$, and ethylene. For comparison, RNA was also extracted from leaves following wounding. Expression of basic chitinase was again investigated for comparison.

In the case of the CF treatment, for both the $S t-W R K Y 1$ and $C h t B 4$ probes, transcript accumulation was detected at $4 \mathrm{~h}$, the earliest time point investigated, and was highest at 8,12 , and $24 \mathrm{~h}$ before decreasing at $48 \mathrm{~h}$ (Fig. 7). In contrast, for SA,
MeJA, wounding (Fig. 7), and ethylene (data not shown), no expression of $S t-W R K Y 1$ was detectable, whereas weak upregulation of endochitinase was observed from between 4 and $12 \mathrm{~h}$ after each treatment.
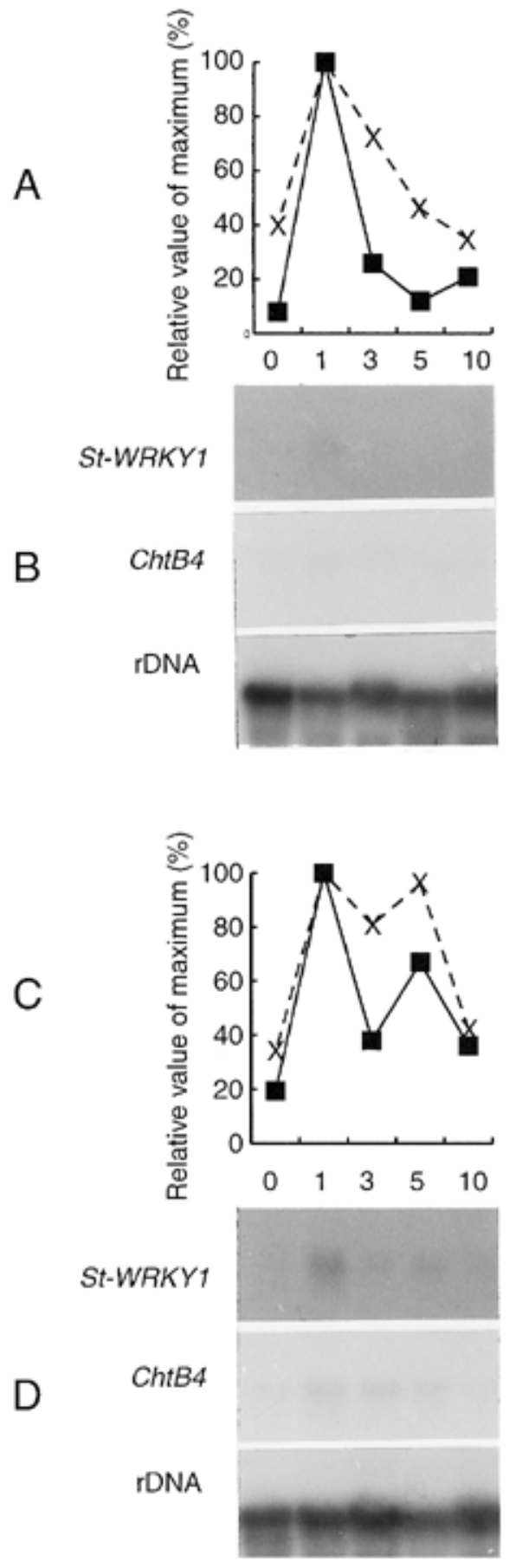

Fig. 6. Northern (RNA) hybridization of the St-WRKY1 gene (StWRKY1), basic chitinase (ChtB4), and, as a control, ribosomal DNA (rDNA), to $20 \mu \mathrm{g}$ of total RNA (each lane) extracted from 'Stirling' uninfected (lane 0 ), and infected $1,3,5$, and $10 \mathrm{~h}$ postinoculation with $\mathbf{B}$, an incompatible isolate and $\mathbf{D}$, a compatible isolate of Phytophthora infestans. The equivalent intensities of hybridized bands obtained from $\mathbf{B}$ and $\mathbf{D}$ after densitometric scanning are shown in $\mathbf{A}$ and $\mathbf{C}$, respectively. The amounts of $S t-W R K Y 1$ (匹) and ChtB4 (X) transcripts were normalized by comparison to rDNA hybridization and were plotted as a percentage of the highest value for each interaction. 


\section{Cell wall-degrading enzymes elicit upregulation of St-WRKY1.}

It has been shown previously that cell wall-degrading enzymes from soft rot erwinias play a crucial role in the interaction with the host plant. In particular, pectinases act not only as virulence determinants but also induce a variety of plant defense responses (Hinton et al. 1989; Palva et al. 1993; Vidal et al. 1997). Oligogalacturonides (OGA) generated by pectin breakdown induce resistance to E. carotovora subsp. atroseptica in potato (Wegener et al. 1996) and have recently been shown to upregulate genes involved in jasmonate production in Arabidopsis (Norman et al. 1999). Given that treatment with E. carotovora subsp. carotovora $\mathrm{CF}$ was able to strongly induce the expression of St-WRKY1 after $4 \mathrm{~h}$ (Fig. 7), we investigated whether individual cell wall-degrading enzymes could induce the expression of this gene. Potato leaves were infiltrated with acellular extracts from recombinant Escherichia coli containing equivalent activity $\left(0.5 A_{265} \mathrm{~min}^{-1} \mathrm{ml}^{-1}\right)$ of pectate lyase $(\mathrm{Pel})$ enzyme produced by either pelA, pelB, pelC, or pelD genes cloned into high-copy-number plasmids. Northern analysis $1 \mathrm{~h}$ after infiltration revealed upregulation of St-WRKY1 by PelB and PelD, whereas PelA and PelC and the supernatant from nonrecombinant Escherichia coli failed to elicit such expression (Fig. 8). Although a range of enzyme dilutions and time points after infiltration would be required to fully characterize the Pel-responsive induction of $S t-W R K Y 1$, this preliminary result clearly suggests that either specific recognition of Pel polypeptides or the pectinolytic degradation of the plant cell wall to generate OGA elicitors contributes to triggering $S t$-WRKY1 expression.

\section{DISCUSSION}

We described the characterization of a potato gene that is upregulated in leaves after inoculation with $E$. carotovora subsp. atroseptica. A full-length cDNA, St-WRKY1, was cloned and encodes a putative group 2 member of the WRKY DNAbinding protein family (Rushton et al. 1996). WRKYs are elicitor-induced proteins that bind to the sequence TGAC, or W box, in the promoters of $P R$ genes (Rushton and Somssich 1998) and appear to be responsible for upregulation of these genes (Rushton et al. 1996). In addition to the WRKY domain implicated in binding, St-WRKY1 contains a putative nuclear localization site and a potential site for activation by protein kinase C. Phosphorylation of WRKY proteins has been suggested to play a role in their activation (Yang et al. 1999) and, indeed, a functional homolog of protein kinase $\mathrm{C}$ participates in elicitor activation of defense responses in potato (Subramaniam et al. 1999).

The only conserved region between WRKY proteins is the 56- to 59-aa WRKY domain defined by Eulgem et al. (1999). An alignment of such domains from 61 proteins revealed that they fall into at least four clades, two of which (C-terminal domains from group 1 proteins and $\mathrm{S} 1$ domains from group 2 proteins) are related. All $\mathrm{N}$ - and C-terminal domains from group 1 proteins form two respective clades, with at least 11 conserved amino acid differences existing between them. The majority of these differences were found in the zinc finger region, known to be involved in interactions with either DNA or other proteins. Indeed, Eulgem et al. (1999), Ishiguro and Nakamura (1994), and de Pater et al. (1996) independently demonstrated that the C-terminal WRKY domains of three group 1 proteins, WRKY1, SPF1, and ZAP1, respectively (Fig. 3, rows 3, 1, and 9, respectively), all bind to $\mathrm{W}$ boxes, whereas their N-terminal domains do not. Seven out of nine amino acids that are conserved in C-terminal but not present in the N-terminal domains also occur in the St-WRKY1 domain. If the St-WRKY1 domain binds to $\mathrm{W}$ boxes, these amino acids will be candidates for manipulation to investigate WRKY DNA-binding function in detail.

A WRKY-like gene in tobacco, TDBA12, is induced specifically during the HR to Tobacco mosaic virus (TMV), suggesting that WRKY proteins may be involved in resistance to pathogens (Yang et al. 1999). St-WRKY1 is also a pathogeninducible gene but, in contrast to TDBA12, it appears to be upregulated in both compatible and incompatible interactions between potato and the oomycete $P$. infestans. Nevertheless, the coregulation of $S t-W R K Y I$ with endochitinase in these interactions suggests that it is a component of a defense-related pathway.

Recently, we demonstrated the upregulation of a potato cysteine protease gene (cyp) in a number of resistant interactions with $P$. infestans (Avrova et al. 1999). The same interactions were used to study St-WRKY1 expression here. Whereas cyp

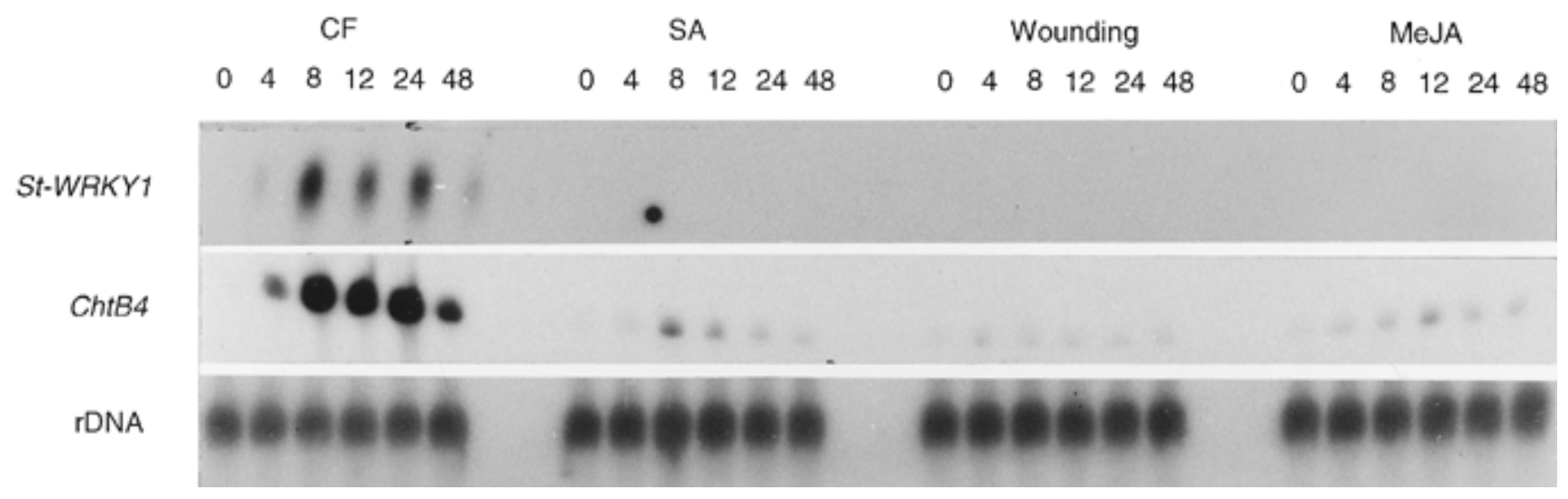

Fig. 7. Northern (RNA) hybridization of the $S t-W R K Y 1$ gene (St-WRKY1), basic chitinase (ChtB4), and, as a control, ribosomal DNA (rDNA), to $20 \mu \mathrm{g}$ of total RNA (each lane) extracted from potato leaf material untreated (0), and treated for 4, 8, 12, 24, and 48 h with Erwinia carotovora subsp. carotovora culture filtrate (CF), salicylic acid (SA), wounding (wounding), and methyl jasmonate (MeJA). 
was only induced at 15 hpi in cultivars following activation of an $R$ gene, the upregulation of St-WRKYl, both when the $R$ gene is activated and when it is not activated, from 15 to 72 hpi in these cultivars, implies distinct defense-related pathways. Only in 'Stirling', which has high levels of field resistance and an uncharacterized $R$ gene, was cyp induced in both compatible and incompatible interactions, associating its expression with all forms of resistance to $P$. infestans (Avrova et al. 1999).

In contrast to the WIZZ WRKY gene recently isolated from tobacco (Hara et al. 2000), there was no detectable St-WRKYI expression after wounding, demonstrating that this gene is not involved in a general stress response. In addition, several signaling pathways known to be involved in activation of defenserelated genes (SA, MeJA, and ethylene) also failed to induce $S t$-WRYK1 expression. The failure of SA to upregulate St$W R K Y 1$ was in contrast to the WRKY-like gene isolated in response to TMV infection in tobacco (Yang et al. 1999), suggesting that members of the WRKY family may be differentially regulated. Moreover, this finding is in agreement with Vidal et al. (1997), who proposed that SA is not the signal molecule leading to the early response of plants to E. carotovora. In contrast to the potato- $P$. infestans interactions (Figs. 5 and 6, Northerns), the ChtB4 probe hybridized to chitinase sequences that were upregulated by SA, wounding, and MeJA, showing that not all chitinase genes are coregulated with $S t-W R K Y 1$.

To further investigate regulation of St-WRKYl expression, we used acellular CFs of E. carotovora subsp. carotovora and of Escherichia coli strains expressing different pectate lyase (pel) genes. Pels, the major component of the E. carotovora subsp. carotovora $\mathrm{CF}$, are enzymes that degrade the plant cell wall, releasing unsaturated OGAs (Forrest and Lyon 1990). The upregulation of St-WRKY1 after treatment with Pel extracts may be triggered either by recognition of the enzyme itself or by the OGAs derived from plant cell wall breakdown. The latter explanation seems more likely, because OGAs have previously been demonstrated to elicit the accumulation of phytoalexins (Davis et al. 1984) and expression of defense-related genes (Norman et al. 1999) in plants. Nevertheless, differential regulation of $S t-W R K Y 1$ by the different Pel enzymes suggests that the degradation products have different elicitor activities. This could be due to the degree of polymerization of the OGAs.

Elicitor induction of $S t-W R K Y 1$ by OGAs suggests that this gene would be upregulated by any pathogen that generates such breakdown products. Its induction at the $1 \mathrm{hpi}$ time points for both compatible and incompatible interactions with $P$. infestans concurs with this. The reason for a phasic pattern of St-WRKY1 and endochitinase gene expression in the potato- $P$. infestans interaction is unclear, although biphasic chitinase gene expression has been observed before in Vitis vinifera in response to fungal challenge (Busam et al. 1997). It is possible that the induction of St-WRKY1 at 1 hpi reflects initial penetration of the epidermis cells, when OGAs are being generated from cell wall breakdown. The lower levels of expression of the gene from 3 to 15 hpi may reflect the biotrophic phase of infection, when the intracellular haustorium is formed. The later upregulation of $S t-W R K Y 1$ from 15 to $72 \mathrm{hpi}$ would correlate with the necrotrophic phase of infection, again when significant levels of OGAs are generated by cell wall breakdown. These time points agree with microscopic studies of the potatoP. infestans interaction by Cuypers and Hahlbrock (1987).
Finally, relatively weaker levels of detectable $S t$-WRKY1 expression in the incompatible than in the compatible interaction after 15 hpi would suggest that the $R$ genes studied in this work are activated during the 1- to 15 -hpi period. Indeed, the specific expression of the cyp gene at $15 \mathrm{hpi}$ in the same incompatible interactions (Avrova et al. 1999) correlates well with this.

\section{MATERIAL AND METHODS}

Plant material and inoculation

with $E$. carotovora subsp. atroseptica and $P$. infestans.

Potato cv. Stirling was used for isolating genes that respond rapidly to challenge with E. carotovora subsp. atroseptica. Detached leaves were vacuum infiltrated with a suspension of E. carotovora subsp. atroseptica at $10^{8} \mathrm{CFU} \mathrm{ml}^{-1}$ in $10 \mathrm{mM}$ $\mathrm{MgSO}_{4}$ for $15 \mathrm{~min}$, and incubated at $18^{\circ} \mathrm{C}$ for $1 \mathrm{~h}$ (or additional time points to extract RNA for Northern blotting), before freezing in liquid nitrogen and storing at $-80^{\circ} \mathrm{C}$.

To investigate the expression of genes after challenge with $P$. infestans, four cultivars were used: Bintje, which is free of $R$ genes and has a field resistance rating of only 2 according to the International 1-to-9 scale of increasing resistance (National Institute of Agricultural Botany [NIAB] 1999); Stirling, with high field resistance (rating 8) (NIAB 1999) and an uncharacterized $R$ gene (Milbourne 1999); and two genotypes of Black's differential series (Black et al. 1953) Pentland Ace and $1512 \mathrm{c}(16)$ (containing the $R 3$ and $R 2$ genes, respectively) that, when included in SCRI field trials of breeders lines, have been allocated a field resistance rating of 2 (averaged over 10 years; H. Stewart, unpublished data). In all cases, $P$. infestans inoculations were made with either a race 1,4 isolate, which gives a clear incompatible interaction with 'Stirling', 'Pentland Ace', and '1512 c(16)', or with a race 1,2,3,4,6,7 isolate, which gives a compatible interaction with 'Pentland Ace' and '1512 c(16)' and produces very slowly developing lesions with 'Stirling'. The races were isolated from potato crops in Scotland during the previous growing season, maintained on RyeA agar over winter and on detached potato leaflets prior to use. Both races gave a clear susceptible interaction with 'Bintje'. To allow for variation in response, five glasshousegrown plants of each cultivar were sprayed with a suspension of zoospores $\left(5 \times 10^{4} \mathrm{ml}^{-1}\right)$, as described by Stewart et al.

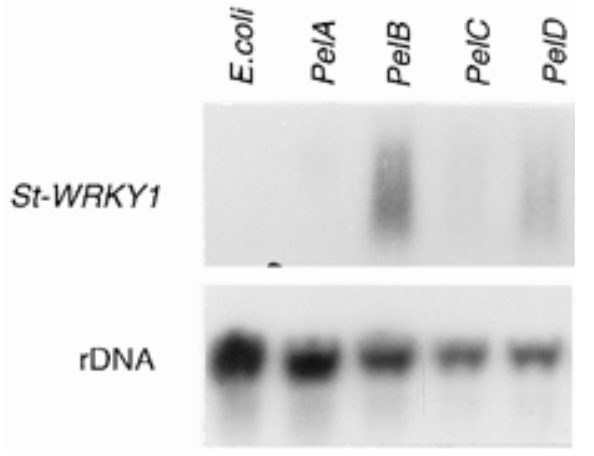

Fig. 8. Northern (RNA) hybridization of the St-WRKY1 gene (St$W R K Y 1$ ) and, as a control, ribosomal DNA (rDNA) to $20 \mu \mathrm{g}$ of total RNA (each lane) extracted from potato leaf material $1 \mathrm{~h}$ after treatment with culture filtrates from Escherichia coli and recombinant Escherichia coli expressing the Erwinia carotovora subsp. carotovora genes PelA, $P e l B, P e l C$, and PelD (lane 5). 
(1983), and leaf material pooled prior to RNA extraction. In each case, RNAs from uninfected leaves were prepared as controls. Additional plants (inoculated and uninoculated) kept as controls for 5 days after inoculation showed a clear difference between 'Stirling' plants inoculated with the different races (data not shown), but similar levels of infection on 'Bintje'.

\section{SSH to generate an enriched cDNA library and the isolation of $S t-W R K Y 1$ cDNA.}

RNA was extracted from 'Stirling' leaves vacuum infiltrated with E. carotovora subsp. atroseptica using an RNeasy Plant Minikit (Qiagen, Hilden, Germany). Double-stranded cDNA was synthesized from the RNA using the First-Strand cDNA Synthesis Kit (Amersham Pharmacia Biotech, Little Chalfont, U.K.) and the Riboclone cDNA Synthesis System (Promega, Madison, WI, U.S.A.).

SSH was carried out using the Clontech PCR-Select cDNA Subtraction Kit (protocol PT1117-1; Clontech, Palo Alto, CA. U.S.A.). Leaves infiltrated with E. carotovora subsp. atroseptica for $1 \mathrm{~h}$ were used to provide the tester cDNA and leaves infiltrated with $\mathrm{MgSO}_{4}$ provided the driver cDNA to remove common sequences. A subtraction of 1,000:1 (driver to tester) cDNA was used. Following SSH, amplification products were size fractionated by gel electrophoresis to give cDNA fragments greater than $400 \mathrm{bp}$ in size. These were purified with the Promega Wizard PCR Preps Kit, cloned using the Promega pGEM-T Vector Cloning Kit, and transformed into Ultracompetent Escherichia coli XL2-blue MRF' cells (Stratagene, La Jolla, CA, U.S.A.). Clones were grown in 384-well microtiter dishes, blotted onto nylon filters, and screened by hybridization using tester and driver probe cDNAs as described previously (Birch et al. 1999). Plasmid preparations (Qiagen Plasmid Miniprep Kit) of clones hybridizing only to the tester probe, or not hybridizing to either probe, were sequenced (ABI PRISM Dye Terminator Cycle Sequencing Kit and ABI Model 377 DNA Sequencer, Perkin Elmer, Warrington, U.K.) with the Promega M13 forward primer. Sequences were compared with international database sequences using BLASTX (Altschul et al. 1990). From the A1 clone sequence, the primer WRKY-F (5'-GCCAGGTTGATATTCTTGATGATG-3') was designed and used with an oligo deoxyribosylthymine primer for 3' RACE. From the 3' RACE product sequence, the primer WRKY-R4 (5'-ATGGGATGTGAATGCATGCCTTC-3') was designed and used with the adapter primer from the Marathon cDNA Amplification Kit (Clontech) for the 5' RACE. The full cDNA was obtained by amplification from cDNA of leaves infiltrated with $P$. infestans 72 hpi with the primers W-S1 (5'ACGTTTAAACCATTCTCAGAAATAGC-3') and W-S2 (5'ACCTCGAGATACATGCCTTACTAGGC-3') and cloned into pGEM-T (Promega), after which both strands were sequenced.

\section{RNA extraction and Northern hybridization.}

RNA was prepared from leaves with the RNeasy Plant Minikit (Qiagen) or following the method from Verwoerd et al. (1989) when it was intended to generate cDNA or Northern blots, respectively. RNA filters were prepared by separating $20 \mu \mathrm{g}$ of denatured total RNA by gel electrophoresis, and transferring onto Amersham Hybond N+ (Amersham Pharmacia Biotech) membranes following the procedure of Sambrook et al. (1989). PCR products purified through Wizard columns (Promega) were used to generate probes by random labeling with $\left[\alpha^{32} \mathrm{P}\right] \mathrm{dCTP}$ and the High Prime Kit (Boehringer $\mathrm{GmbH}$, Mannheim, Germany). Hybridization and washes were performed as described by Sambrook et al. (1989).

\section{Treatment of potato leaves with SA, MeJA, ethylene, wounding, and $E$. carotovora subsp. carotovora $\mathrm{CF}$.}

RNA was extracted for Northern analysis from leaf material treated with E. carotovora subsp. carotovora CF, MeJA, SA, and ethylene. For comparison, RNA was also extracted from leaves following wounding. In each case, to allow for variation, RNA from the leaves of four to eight treated plants was pooled prior to analysis. SA treatment was by spraying with $2 \mathrm{ml}$ of $5 \mathrm{mM}$ SA per plant, as described previously (Vidal et al. 1997), and MeJA, CF, and wounding treatments were also as described previously (Norman et al. 1999). Ethylene treatments were performed in an air-tight chamber at $70 \%$ humidity, containing $50 \mathrm{ppm}$ of ethylene. Ethylene concentration was monitored using a photoionizer (PI 101 trace gas ionizer; HNU Systems Inc., Newton, MA, U.S.A.).

\section{Bacterial strains and production of pectin-degrading enzymes.}

The strains used in this study are the wild-type E. carotovora subsp. atroseptica SCRI1039 (Hyman et al. 1997), E. carotovora subsp. carotovora SCC193 (Pirhonen et al. 1988), and Escherichia coli TG1 (Hinton et al. 1989) with plasmids pH5 (pelA cloned into pBR322), pB6 (pelB cloned into pUC8), pJS619 (pelC cloned into pUC19), and pJS616 (pelD cloned into pUC19). Bacteria were grown in Luria-Bertani medium (Miller 1972) supplemented with ampicillin (100 $\mu \mathrm{g}$ $\mathrm{ml}^{-1}$ when necessary). Bacteria CFs were obtained by filter sterilization of supernatant from E. carotovora subsp. carotovora cultures. The acellular Pel enzyme extracts were prepared from overnight recombinant Escherichia coli cultures as follows: harvested cells were washed twice in Tris- $\mathrm{HCl} 20 \mathrm{mM}$, $\mathrm{pH} 8.6$, before sonication. Cell debris was eliminated by centrifugation and the Pel activity was tested as described in McMillan et al. (1994). 'Stirling' leaves were vacuum infiltrated (20 min) with $40 \mathrm{ml}$ of water containing $0.5 \mathrm{ml}$ of Pel extracts. Leaves were harvested $1 \mathrm{~h}$ after incubation at $18^{\circ} \mathrm{C}$ and frozen in liquid nitrogen prior to RNA extraction.

\section{ACKNOWLEDGMENTS}

PRJB, JH, AOA, DEC, IKT, HES, and GDL are grateful for financial support from the Scottish Executive Rural Affairs Department (SERAD), and $\mathrm{AD}$ and $\mathrm{MM}$ to the European Union (ERBIC-15-CT960908).

\section{LITERATURE CITED}

Altschul, S. F., Gish, W., Miller, W., Myers, E. W., and Lipman D. 1990. Basic local alignment search tool. J. Mol. Biol. 215:403-410.

Avrova, A. O., Stewart, H. E., De Jong, W. D., Heilbronn, J., Lyon, G. D., and Birch, P. R. J. 1999. A cysteine protease gene is expressed early in resistant potato interactions with Phytophthora infestans. Mol. Plant-Microbe Interact. 12:1114-1119.

Beerhues, L., and Kombrink, E. 1994. Primary structure and expression of mRNAs encoding basic chitinase and 1,3-beta-glucanase in potato. Plant Mol. Biol. 24:353-367.

Birch, P. R. J., Avrova, A. O., Duncan, J. M., Lyon, G. D., and Toth, R. L. 1999. Isolation of potato genes that are induced during an early stage of the hypersensitive response to Phytophthora infestans. Mol. Plant-Microbe Interact. 12:356-361. 
Black, W., Mastenbroek, C., Mills, W. R., and Peterson, L. C. 1953. A proposal for an international nomenclature of races of Phytophthora infestans and of genes controlling immunity in Solanum demissum derivatives. Euphytica 2:173-178.

Busam, G., Kassemeyer, H.-H., and Matern, U. 1997. Differential expression of chitinases in Vitis vinifera $\mathrm{L}$. responding to systemic acquired resistance activators of fungal challenge. Plant Physiol. 115: 1029-1038

Cuypers, B., and Hahlbrock, K. 1988. Immunohistochemical studies of compatible and incompatible interactions of potato leaves with Phytophthora infestans and of the nonhost response to Phytophthora megasperma. Can. J. Bot. 66:700-705.

Czernic, P., Visser, B., Sun, W., Savoure, A., Deslandes, L., Marco, Y., Van Montagu, M., and Verbruggen, N. 1999. Characterization of an Arabidopsis thaliana receptor-like protein kinase gene activated by oxidative stress and pathogen attack. Plant J. 18:321-327.

Dangl, J. L., Dietrich, R. A., and Richberg, M. H. 1996. Death don't have no mercy: Cell death programs in plant-microbe interactions. Plant Cell 8:1793-1807.

Davis, K. R., Lyon, G. D., Darvill, A. G., and Albersheim, P. 1984. Hostpathogen interactions. XXV. Endopolygalacturonic acid lyase from Erwinia carotovora elicits phytoalexin accumulation by releasing plant cell wall fragments. Plant Physiol. 74:52-60.

de Pater, S., Greco, V., Pham, K., Memelink, J., and Kijne, J. 1996. Characterization of a zinc-dependent transcriptional activator from Arabidopsis. Nucleic Acids Res. 24:4624-4631.

Diatchenko, L., Lau, Y.-F. C., Campbell, A. P., Chenchik, A., Moqadam, F., Huang, B., Lukyanov, S., Lukyanov, K., Gurskaya, N., Sverdlov, E. D., and Siebert, P. D. 1996. Suppression subtractive hybridization: A method for generating differentially regulated or tissue-specific cDNA probes and libraries. Proc. Natl. Acad. Sci. U.S.A. 93:6025-6030.

Eulgem, T., Rushton, P. J., Schmelzer, E., Hahlbrock, K., and Somssich, I. E. 1999. Early nuclear events in plant defence signalling: Rapid gene activation by WRKY transcription factors. EMBO J. 18:4689-4699.

Forrest, R. S., and Lyon, G. D. 1990. Substrate degradation patterns of polygalacturonic acid lyase from Erwinia carotovora and Bacillus polymyxa, and release of phytoalexin-eliciting oligosaccharides from potato cell walls. J. Exp. Bot. 41:481-488.

Fukuda, Y., and Shinshi, H. 1994. Characterization of a novel cis-acting element that is responsive to a fungal elicitor in the promoter of a tobacco class I chitinase gene. Plant Mol. Biol. 24:485-493.

Hammond-Kosack, K. E., and Jones, J. D. G. 1997. Plant disease resistance genes. Annu. Rev. Plant Physiol. Plant Mol. Biol. 48:575-607.

Hara, K., Yagi, M., Kusano, T., and Sano, H. 2000. Rapid systemic accumulation of transcripts encoding a tobacco WRKY transcription factor upon wounding. Mol. Gen. Genet. 263:30-37.

Hinton, J. C. D., Sidebotham, J. M., Gill, D. R., and Salmond, G. P. C. 1989. Extracellular and periplasmic isoenzymes of pectate lyase from Erwinia carotovora ssp. carotovora belong to different gene families. Mol. Microbiol. 3:1785-1795.

Hyman, L. J., Dewasmas, V., Toth, I. K., and Perombelon, M. C. M. 1997. Improved PCR detection sensitivity of Erwinia carotovora subsp. atroseptica in potato peel extract by prior enrichment on a selective medium. Lett. Appl. Microbiol. 25:143-147.

Ishiguro, S., and Nakamura, K. 1994. Characterization of a cDNA encoding a novel DNA-binding protein, SPF1, that recognizes SP8 sequences in the $5^{\prime}$ upstream regions of genes coding for sporamin and beta-amylase from sweet potato. Mol. Gen. Genet. 244:563-571.

Lease, K., Ingham, E., and Walker, J. C. 1998. Challenges in understanding RLK function. Curr. Opin. Plant Biol. 1:388-392.

McMillan, G. P., Barrett, A. M., and Perombelon, M. C. M. 1994. An isoelectric-focusing study of the effect of methyl-esterified pectin substances on the production of extracellular pectin isoenzymes by soft-rot Erwinia spp. J. Appl. Bacteriol. 77:175-184.
Milbourne, D. 1999. Development and assessment of tools and strategies for linkage and QTL analysis in tetraploid potato. Ph.D. thesis. University of Dundee, Dundee, U.K.

Miller, J. F. 1972. Experiments in Molecular Genetics. Cold Spring Harbor Laboratory Press, Cold Spring Harbor, NY, U.S.A..

National Institute of Agricultural Botany (NIAB). 1999. Potato Variety Handbook 2000. Recommended List of Potatoes. E \& E Plumridge, Linton, Cambridge.

Nicholas, K. B., Nicholas, H. B., Jr., and Deerfield, D. W., II. 1997. GeneDoc: Analysis and visualization of genetic variation. Embnew. News 4:14.

Norman, C., Vidal, S., and Palva, E. 1999. Oligogalacturonide-mediated induction of a gene involved in jasmonic acid synthesis in response to the cell-wall-degrading enzymes of the plant pathogen Erwinia carotovora. Mol. Plant-Microbe Interact. 12:640-644.

Palva, T. K., Holmstrom, K.-O., Heino, P., and Palva, E. T. 1993. Induction of the plant defense response by exoenzymes of Erwinia carotovora subsp. carotovora. Mol. Plant-Microbe Interact. 6:190-196.

Pirhonen, M., Heino, P., Helander, I., Harju, P., and Palva, E. T. 1988. Bacteriophage T4 resistant mutants of the plant pathogen Erwinia carotovora. Microb. Pathog. 4:359-367.

Reymond, P., and Farmer, E. E. 1998. Jasmonate and salicylate as global signals for defense gene expression. Curr. Opin. Plant Biol. 1:404-411.

Rushton, P. J., Macdonald, H., Huttly, A. K., Lazarus, C. M., and Hooley, R. 1995. Members of a new family of DNA-binding proteins bind to a conserved cis-element in the promoters of $a$-Amy2 genes. Plant. Mol. Biol. 29:691-702.

Rushton, P. J., and Somssich, I. E. 1998. Transcriptional control of plant genes responsive to pathogens. Curr. Opin. Plant Biol. 1:311-315.

Rushton, P. J., Torres, J. T., Parniske, M., Wernert, P., Hahlbrock, K., and Somssich, I. E. 1996. Interaction of elicitor-induced DNA-binding proteins with elicitor response elements in the promoters of parsley PR1 genes. EMBO J. 15:5690-5700.

Sambrook, J., Fritsch, E. F., and Maniatis, T. 1989. Molecular Cloning A Laboratory Manual. Cold Spring Harbor Laboratory, Cold Spring Harbor, NY, U.S.A.

Somssich, I. E., and Hahlbrock, K. 1998. Pathogen defence in plants-A paradigm of biological complexity. Trends Plant Sci. 3:86-90.

Stewart, H. E., Flavelle, P. H., McCalmont, D. C., and Wastie, R. L. 1983. Correlation between glasshouse and field tests for resistance to foliage blight caused by Phytophthora infestans. Potato Res. 26:41-48.

Subramaniam, R., Despres, C., and Brisson, N. 1999. A functional homolog of mammalian protein kinase $\mathrm{C}$ participates in the elicitorinduced defense response in potato. Plant Cell 9:653-664.

Thompson, J. D., Higgins, D. G., and Gibson, T. J. 1994. CLUSTAL W: Improving the sensitivity of multiple sequence alignment through sequence weighting, position-specific gap penalties and weight matrix choice. Nucleic Acids Res. 22:4673-4680.

Verwoerd, T. C., Dekker, B. M., and Hoekema, A. 1989. A small-scale procedure for the rapid isolation of plant RNAs. Nucleic Acids Res. $17: 2362$.

Vidal, S., Ponce de León, I., Denecke, J., and Palva, E. T. 1997. Salicylic acid and the plant pathogen Erwinia carotovora induce defense genes via antagonistic pathways. Plant J. 11:115-123.

Wang, Z., Yang, P., Fan, B., and Chen, Z. 1998. An oligo selection procedure for identification of sequence-specific DNA-binding activities associated with plant defense. Plant J. 16:515-522.

Wegener, C., Bartling, S., Olsen, O., Weber, J., and von Wettstein, D 1996. Pectate lyase in transgenic potatoes confers pre-activation of defence against Erwinia carotovora. Physiol. Mol. Plant Pathol. 49:359-376.

Yang, P., Chen, C., Wang, Z., Fan, B., and Chen, Z. 1999. A pathogenand salicylic acid-induced WRKY DNA-binding activity recognizes the elicitor response element of the tobacco class I chitinase gene promoter. Plant J. 18:141-149. 